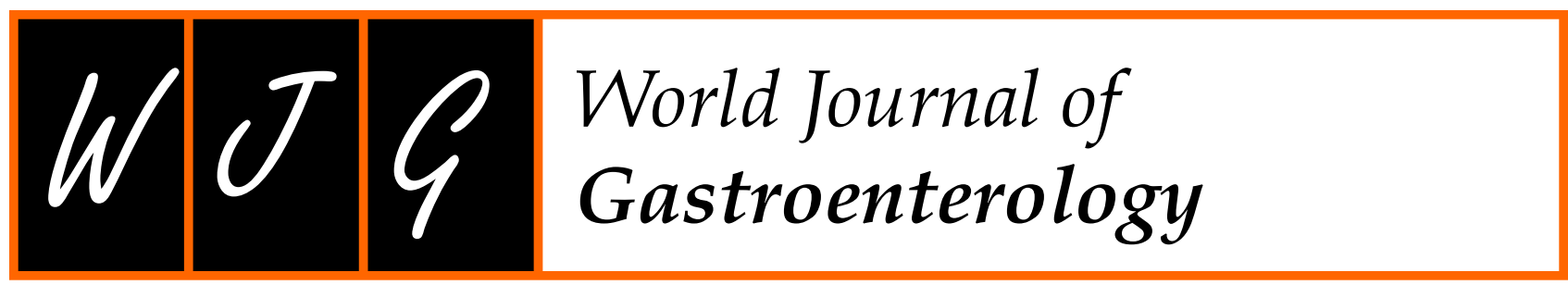

Submit a Manuscript: https:/ / www.f6publishing.com

World J Gastroenterol 2020 October 21; 26(39): 6027-6036

\title{
Real-world treatment attrition rates in advanced esophagogastric cancer
}

\author{
Erica S Tsang, Howard J Lim, Daniel J Renouf, Janine M Davies, Jonathan M Loree, Sharlene Gill
}

ORCID number: Erica S Tsang 00000003-2317-2721; Howard J Lim 00000002-5814-714X; Daniel J Renouf 0000-0002-7597-6089; Janine M Davies 0000-0003-3834-6835; Jonathan M Loree 0000-0001-81892132; Sharlene Gill 0000-0003-33063617.

Author contributions: Tsang ES and Gill S were responsible for conception and design, collection and assembly of data, and data analysis and interpretation; all authors contributed to manuscript writing and provided final approval of the manuscript.

\section{Institutional review board}

statement: This study was reviewed and approved by Systemic Therapy - Vancouver (BC Cancer), REB number H19-01865.

Conflict-of-interest statement: All authors have no any conflicts of interest.

\section{Data sharing statement: No} additional data.

\section{Open-Access: This article is an} open-access article that was selected by an in-house editor and fully peer-reviewed by external reviewers. It is distributed in accordance with the Creative Commons Attribution NonCommercial (CC BY-NC 4.0)
Erica S Tsang, Howard J Lim, Daniel J Renouf, Janine M Davies, Jonathan M Loree, Sharlene Gill, Department of Medicine, BC Cancer, Vancouver V5Z 4E6, Canada

Erica S Tsang, Howard J Lim, Daniel J Renouf, Janine M Davies, Jonathan M Loree, Sharlene Gill, Division of Medical Oncology, University of British Columbia, Vancouver V5Z 4E6, Canada

Corresponding author: Sharlene Gill, MD, Professor, Department of Medicine, BC Cancer, 600 West 10th Avenue, Vancouver V5Z 4E6, Canada. sgill@bccancer.bc.ca

\section{Abstract \\ BACKGROUND}

Over the last decade, multiple agents have demonstrated efficacy for advanced esophagogastric cancer (EGC). Despite the availability of later lines of therapy, there remains limited real-world data about the treatment attrition rates between lines of therapy.

\section{AIM}

To characterize the use and attrition rates between lines of therapy for patients with advanced EGC.

\section{METHODS}

We identified patients who received at least one cycle of chemotherapy for advanced EGC between July 1, 2017 and July 31, 2018 across six regional centers in British Columbia (BC), Canada. Clinicopathologic, treatment, and outcomes data were extracted.

\section{RESULTS}

Of 245 patients who received at least one line of therapy, median age was 66 years (IQR 58.2-72.3) and 186 (76\%) were male, Eastern Cooperative Oncology Group (ECOG) performance status 0/1 (80\%), gastric vs GEJ (36\% vs 64\%). Histologies included adenocarcinoma (78\%), squamous cell carcinoma $(8 \%)$, and signet ring (14\%), with $31 \%$ HER2 positive. $72 \%$ presented with de novo disease, and $25 \%$ had received previous chemoradiation. There was a high level of treatment attrition, with patients receiving only one line of therapy $n=122,50 \%$ ), two lines $n$ $=83,34 \%$ ), three lines $n=34,14 \%$ ), and four lines $n=6,2 \%)$. Kaplan-Meier analysis demonstrated improved survival with increasing lines of therapy (median overall survival 7.7 vs 16.6 vs 22.8 vs 40.4 mo, $P<0.05$ ). On multivariable Cox regression, improved survival was associated with better baseline ECOG and 
license, which permits others to distribute, remix, adapt, build upon this work non-commercially, and license their derivative works on different terms, provided the original work is properly cited and the use is non-commercial. See: htt p://creativecommons.org/License s/by-nc/4.0/

Manuscript source: Unsolicited manuscript

Received: May 10, 2020

Peer-review started: May 10, 2020

First decision: June 13, 2020

Revised: June 24, 2020

Accepted: September 25, 2020

Article in press: September 25, 2020

Published online: October 21, 2020

P-Reviewer: D'Ugo DM, Zhe MM

S-Editor: Ma YJ

L-Editor: A

P-Editor: Zhang YL increased lines of therapy $(P<0.05)$.

\section{CONCLUSION}

The steep attrition rates between therapies highlight the unmet need for more efficacious early-line treatment options for patients with advanced EGC.

Key Words: Esophagogastric cancer; Gastric cancer; Treatment attrition; Systemic therapy; Treatment outcomes; Real-world evidence

CThe Author(s) 2020. Published by Baishideng Publishing Group Inc. All rights reserved.

Core Tip: Despite the availability of later lines of therapy for esophagogastric cancer (EGC), there remains limited real-world data about the treatment attrition rates between lines of therapy. In this population-based analysis, we characterize the use and treatment attrition rates for patients with advanced EGC. Among 245 patients, there was a high level of treatment attrition, with $50 \%$ receiving one line of therapy, $34 \%$ receiving two lines, and 14\% receiving three-lines. Improved survival was associated with better baseline Eastern Cooperative Oncology Group and increased lines of therapy. This real-world analysis demonstrating such steep attrition rates highlights the unmet need for more efficacious early-line treatment options.

Citation: Tsang ES, Lim HJ, Renouf DJ, Davies JM, Loree JM, Gill S. Real-world treatment attrition rates in advanced esophagogastric cancer. World J Gastroenterol 2020; 26(39): 60276036

URL: https://www.wjgnet.com/1007-9327/full/v26/i39/6027.htm

DOI: https://dx.doi.org/10.3748/wjg.v26.i39.6027

\section{INTRODUCTION}

Gastric cancer is the fourth most common type of cancer, while esophageal cancer remains the eight most common type of cancer ${ }^{[1]}$. Locally advanced unresectable and metastatic disease in both sites have dismal outcomes, with 5-year survival rates measuring less than $4 \%^{[2,3]}$. The current standard of care for advanced esophagogastric cancer is systemic chemotherapy with a first-line platinum and fluoropyrimidine combination ${ }^{[4]}$. Rates of second-line treatment have been reported to be between $14 \%$ and $75 \%{ }^{[5,6]}$. A retrospective Italian study early in the ramucirumab era examined rates of second-line treatment and reported a range of $7 \%-41 \%$; however, this was limited by a small number of patients who received ramucirumab, which has now been established as a standard second-line regimen ${ }^{[7]}$.

Over the last decade, multiple agents have also been tried in later line settings, including ramucirumab, irinotecan, trifluridine/tipiracil, and immunotherapy ${ }^{\left[{ }^{-11}\right]}$. Current trials such as the CCTG GA.3 trial focus on examining the role of regorafenib in the later line setting (NCT02773524). It is important to gauge the real-world use of multiple lines of therapy for patients with metastatic esophagogastric cancer, beyond a clinical trial population.

The objectives of this study were to characterize the attrition rates between lines of therapy for patients with unresectable locally advanced or metastatic esophagogastric cancer (EGC), and to identify prognostic factors for improved survival.

\section{MATERIALS AND METHODS}

In British Columbia (BC), Canada, BC Cancer is the provincial institution responsible for overseeing cancer-related care for 4.4 million residents, including the development of cancer therapy guidelines, provision of radiation therapy, and funding for all approved systemic therapies. The BC Cancer Provincial Pharmacy Database provides and holds records for all provincially funded systemic therapies across six cancer centres in BC.

We sought to characterize the use and attrition rates between lines of therapy for 
patients with advanced EGC, defined as either esophageal, gastroesophageal junction, or gastric cancer. We identified patients who received at least one cycle of systemic therapy for advanced histology-confirmed EGC between July 1, 2017 and July 31, 2018 from the BC Cancer Provincial Pharmacy Database. These dates were chosen based on the funding and availability of ramucirumab and paclitaxel after May 2017, and to allow for sufficient follow-up. Clinicopathologic data, treatment details, and survival outcomes were extracted by chart review. Patients who continued on treatment were censored at the date of last contact. Given the focus on systemic therapy, data regarding radiotherapy for palliative purposes was not explicitly included. This study was approved by the BC Cancer Research Ethics Board.

\section{Statistical analysis}

Baseline clinicopathologic characteristics and delivery of multiple lines of therapies were reported using descriptive statistics, with differences in variables analyzed using the chi-square or Wilcoxon rank-sum tests where appropriate. Overall survival (OS) was calculated from the date of diagnosis of advanced disease to date of death or date of last follow-up. Univariable and multivariable logistic regression analyses exploring factors associated with improved survival were performed with the Cox proportional hazards model. Variables included in the Cox proportional hazards models were selected based on known prognostic factors and those significant on univariable analysis $(P<0.05)$. OS was estimated using the Kaplan-Meier method, with the logrank test used to compare differences. All tests were two-sided, and a $P$ value of $<0.05$ was considered statistically significant. Stata version 15.1 was used for all statistical analyses (Stata, College Station, TX, United States).

\section{RESULTS}

Of 245 patients who received at least one line of therapy, median age was 66 years (IQR 58.2-72.3) and 186 (76\%) were male. Baseline Eastern Cooperative Oncology Group (ECOG) performance status was $0-1$ in $80 \%$, and site of primary was gastric vs GEJ (36\% vs 64\%). Histologies included adenocarcinoma $(78 \%)$, squamous cell carcinoma (8\%), and signet ring (14\%), with 31\% HER2 positive. $72 \%$ presented with de novo disease, and $25 \%$ had received previous chemoradiation. Further clinicopathologic characteristics are detailed in Table 1.

There was a high level of treatment attrition, with $50 \%$ of patients $(n=122)$ receiving only one line of therapy. Distribution across subsequent lines was: two lines $(n=83,34 \%)$, three lines $(n=34,14 \%)$, and four lines $(n=6,2 \%)$. Patients who received at least two lines of therapy were younger (median age 62.2 vs 67.6 years, $P<0.05$ ) and demonstrated a longer and improved response to first-line systemic therapy compared to those who only received one line of treatment (median duration 5.0 vs $2.7 \mathrm{mo}, P<$ $0.05 ; 50 \%$ complete or partial response $(40 \%$ vs $32 \%, P<0.05)$.

In terms of systemic therapy regimens, ramucirumab and paclitaxel was the most common second line treatment $(62 \%)$, with an objective response (complete or partial response) observed in only $16 \%$ of patients (Table 2 ). In the third-line setting, 5fluorouracil and irinotecan was the most common regimen $(35 \%)$. Fourth-line regimens were largely 5-fluorouracil based, with one of six patients receiving nivolumab.

Kaplan-Meier survival analysis demonstrated improved survival with increasing lines of therapy (median OS 7.7 vs 16.6 vs 22.8 vs 40.4 mo, $P<0.05$; Figure 1 ). On multivariable Cox regression, improved survival was associated with better baseline ECOG and increased lines of therapy $(P<0.05$; Table 3$)$.

\section{DISCUSSION}

In this population-based analysis, we demonstrate high treatment attrition rates among patients with advanced EGC, with only half of patients proceeding to receive two or more systemic therapy regimens. Survival improved with the application of multiple lines of therapy and a good baseline ECOG performance status.

Our findings of high levels of attrition are consistent with other retrospective studies reported in the literature, with a number of these employing electronic health record (EHR) data. Le et al ${ }^{[12]}$ examined EHR data from the Flatiron Health database, and found a $75 \%$ rate of first-line, $32 \%$ rate of second-line, $14 \%$ rate of third-line, and 
Table 1 Baseline characteristics of 245 patients with advanced esophagogastric cancer who received at least one line of systemic therapy

\begin{tabular}{|c|c|c|c|}
\hline & Only one line of therapy $(n=122)$ & At least two lines of therapy $(n=123)$ & $P$ value \\
\hline Median age (IQR) & $68(61.7-73.7)$ & $62(56.1-70.6)$ & $<0.05$ \\
\hline Gender, $n(\%)$ & & & 0.37 \\
\hline Male & $96(79)$ & $90(73)$ & \\
\hline Female & $26(21)$ & $33(27)$ & \\
\hline Ethnicity, $n(\%)$ & & & 0.59 \\
\hline Caucasian & $101(83)$ & $95(77)$ & \\
\hline Asian & $15(12)$ & $21(17)$ & \\
\hline East Asian & $6(5)$ & $6(5)$ & \\
\hline Other & 0 & $1(1)$ & \\
\hline Histology, $n(\%)$ & & & 0.92 \\
\hline Adenocarcinoma & $96(79)$ & $95(77)$ & \\
\hline Squamous cell carcinoma & $9(7)$ & $11(9)$ & \\
\hline Signet ring cell & $17(14)$ & $17(14)$ & \\
\hline HER2 status, $n(\%)$ & & & 0.41 \\
\hline Positive & $27(22)$ & $37(30)$ & \\
\hline Negative & $70(57)$ & $72(59)$ & \\
\hline Unknown & $25(20)$ & $14(11)$ & \\
\hline MMR status by IHC, $n(\%)$ & & & 1.0 \\
\hline Deficient MMR & $1(1)$ & $1(1)$ & \\
\hline Proficient MMR & $34(28)$ & $55(45)$ & \\
\hline Unknown & $87(71)$ & $67(54)$ & \\
\hline Grade, $n(\%)$ & & & 0.14 \\
\hline Well & $3(2)$ & $5(4)$ & \\
\hline Moderate & $30(25)$ & $42(34)$ & \\
\hline Poor & $58(48)$ & $45(37)$ & \\
\hline Unknown & $31(25)$ & $31(25)$ & \\
\hline Site of primary, $n(\%)$ & & & 0.44 \\
\hline Gastric & $44(36)$ & $46(37)$ & \\
\hline GEJ/esophagus & $78(64)$ & $77(63)$ & \\
\hline \multicolumn{4}{|l|}{ Location of metastases, $n(\%)$} \\
\hline Lymph node & $64(52)$ & $54(44)$ & 0.20 \\
\hline Lung & $29(24)$ & $28(67)$ & 0.88 \\
\hline Liver & $39(32)$ & $50(41)$ & 0.18 \\
\hline Peritoneum & $31(25)$ & $23(19)$ & 0.22 \\
\hline Other & $28(23)$ & $16(13)$ & 0.05 \\
\hline Disease presentation, $n(\%)$ & & & 0.89 \\
\hline De novo disease & $87(71)$ & $89(72)$ & \\
\hline Recurrent disease & $35(29)$ & $34(28)$ & \\
\hline Previous chemoradiation, $n(\%)$ & $32(26)$ & $29(24)$ & 0.66 \\
\hline Previous resection, $n(\%)$ & $27(22)$ & $24(20)$ & 0.64 \\
\hline
\end{tabular}


ECOG at baseline, $n(\%)$

0

1

2

Best response to first-line treatment, $n$ (\%)

Complete response

Partial response

Stable disease

Progressive disease

Unknown

Median duration of first-line treatment

Reason for discontinuation of first-line treatment, $n$ (\%)

Progression

Toxicity

Other

Unknown
11 (9)

$83(68)$

$28(23)$

$20(16)$

$58(48)$

$5(4)$

$2.7(0.9-6.1)$

$82(67)$

15 (12)

23 (19)

$2(2)$
0.14

20 (16)

84 (68)

19 (15)

4 (3)

46 (37)

38 (31)

33 (27)

$2(2)$

$5.00(3.5-9.8)$

$<0.05$

0.02

$101(82)$

4 (3)

$17(14)$

1 (1)

IQR: Interquartile range; HER2: Human epidermal growth factor receptor 2; MMR: Mismatch repair; IHC: Immunohistochemistry; GEJ: Gastroesophageal junction.

$6 \%$ rate of fourth-line therapies. We note that this was primarily in a United States community-based practice setting, compared to our Canadian single-payer system. In a similar EHR-based analysis, Barzi et al ${ }^{[13]}$ described a $60 \%$ rate of second-line therapy use. Previous retrospective EHR-based studies have reported an approximately $50 \%$ rate of second-line therapies ${ }^{[14,15]}$. In a Japanese single institution study, Ueno et al ${ }^{[16]}$ reported a $26 \%$ rate of third-line systemic therapy.

Similarly, improved survival outcomes have been associated with an increasing number of lines of therapy and improved baseline performance status ${ }^{[12,17]}$. Fanotto et al ${ }^{[18]}$ described additional prognostic factors, including lower LDH levels and a lower neutrophil/Lymphocyte ratio at the initiation of second-line therapy. There was insufficient LDH data to examine this, and we did not find a similar association with the neutrophil/Lymphocyte ratio.

The survival outcomes and high level of treatment attrition highlight the lethality of EGC. Screening can play a role in detecting these cancers at an earlier stage. While this is feasible in countries with a high incidence rate such as South Korea and Japan, this is not readily available in Canada ${ }^{[19-21]}$. For patients already diagnosed with advanced disease, better risk stratification and more effective frontline therapies are urgently needed. The combined positive score is now used to identify patients who are more likely to benefit from immunotherapy, after the findings from KEYNOTE-181 ${ }^{[22]}$. Improved biomarkers for risk stratification and treatment selection are also being investigated. Despite the work done in molecular subtyping of gastric cancer, there are few actionable targets and significant intratumoral heterogeneity; thus, limiting the role for precision medicine in the upfront treatment setting ${ }^{[23,24]}$. Some markers, such as $M E T$ overexpression, have been associated with poor prognosis and this continues to be studied as a potential actionable target ${ }^{[25,26]}$. In recent years, there has been a shift towards immunotherapy-based combinations, such as in the MORPHEUS umbrella trial ${ }^{[27]}$. It remains to be seen whether this can play an effective earlier-line strategy in patients with advanced EGC.

Limitations of our study include the retrospective nature, which limits causal inference regarding prognostic factors for improved survival. The limited sample size in a Canadian single-payer health system may limit generalizability. However, while our sample size of 245 patients is smaller than the United States nationwide EHR database, our data are manually curated and provide more granularity as a result. There is also selection bias and practitioner variability in defining ECOG performance status, and in offering a subsequent line of therapy. Finally, this study was done prior to the approval and availability of oral trifluridine/tipiracil in the third-line setting, which may influence treatment practices in this population. 
Second-line chemotherapy backbone $[n=123, n(\%)]$

$\begin{array}{lc}\text { 5-FU/oxaliplatin } & 9(7) \\ \text { 5-FU/irinotecan } & 21(17) \\ \text { 5-FU/cisplatin } & 3(2) \\ \text { Ramucirumab/paclitaxel } & 76(62) \\ \text { Docetaxel } & 8(7) \\ \text { Capecitabine } & 2(2) \\ \text { Irinotecan } & 3(2) \\ \text { Trastuzumab alone } & 1(1)\end{array}$

Best response to second-line treatment, $n(\%)$

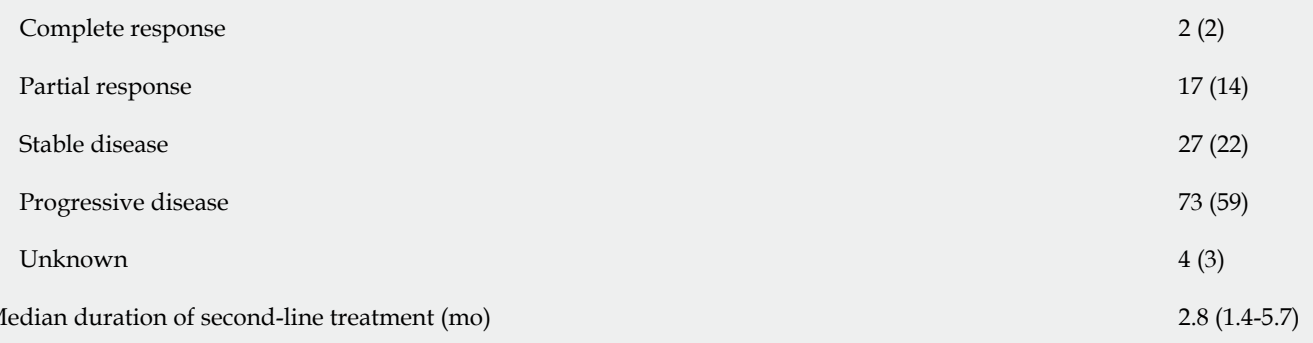

Reason for discontinuation of second-line treatment, $n(\%)$

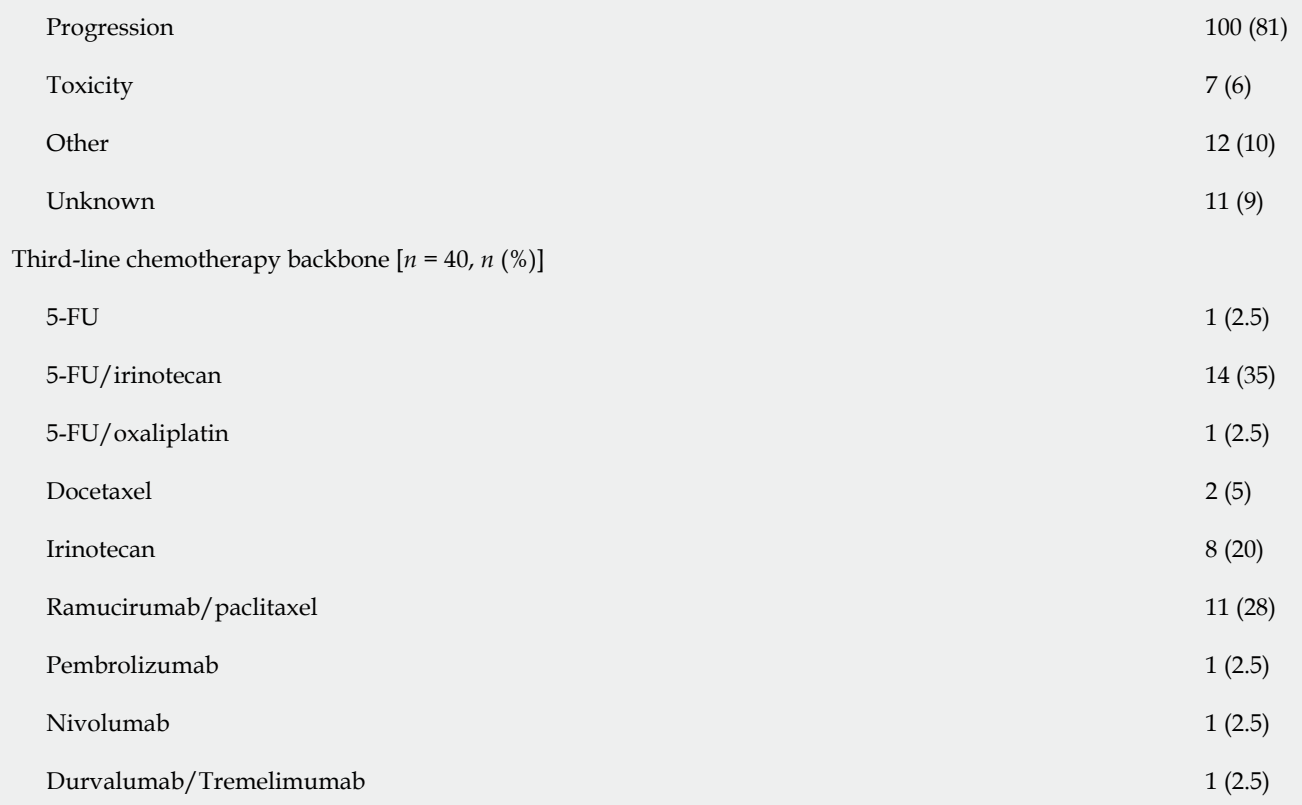




\section{Unknown}

Fourth-line chemotherapy backbone $[n=6, n(\%)]$

5-FU

5-FU/oxaliplatin

5-FU/irinotecan

5-FU/cisplatin

Nivolumab

Best response to fourth-line treatment, $n(\%)$

Complete response

Partial response

Stable disease

Progressive disease

Median duration of fourth-line treatment (mo)

Reason for discontinuation of fourth-line treatment, $n(\%)$

Progression

Toxicity

0

Other

5-FU: 5-fluorouracil.

Table 3 Multivariable Cox regression analysis for overall survival

\begin{tabular}{lll}
\hline & Hazard ratio (95\%Cl) & $P$ value \\
\hline Gender (male vs female) & $1.07(0.77-1.48)$ & 0.69 \\
Baseline ECOG (continuous) & $1.33(1.02-1.73)$ & $\mathbf{0 . 0 4}$ \\
Recurrent disease (vs de novo) & $0.86(0.62-1.19)$ & 0.37 \\
Duration of first-line treatment & $1.00(1.00-1.002)$ & 0.09 \\
Lines of treatment & $0.61(0.50-0.74)$ & $<0.01$ \\
\hline
\end{tabular}

ECOG: Eastern Cooperative Oncology Group.

\section{CONCLUSION}

We present a population-based analysis of real-world use of later-line therapy in patients with advanced EGC. The steep attrition rates between therapies highlight the high symptom burden in this setting and the unmet need for more efficacious earlyline treatment options for patients with advanced EGC. Improved biomarkers may provide informed risk stratification in selecting later lines of treatment, and identifying patients who would derive greater benefit from multiple lines of therapy. 


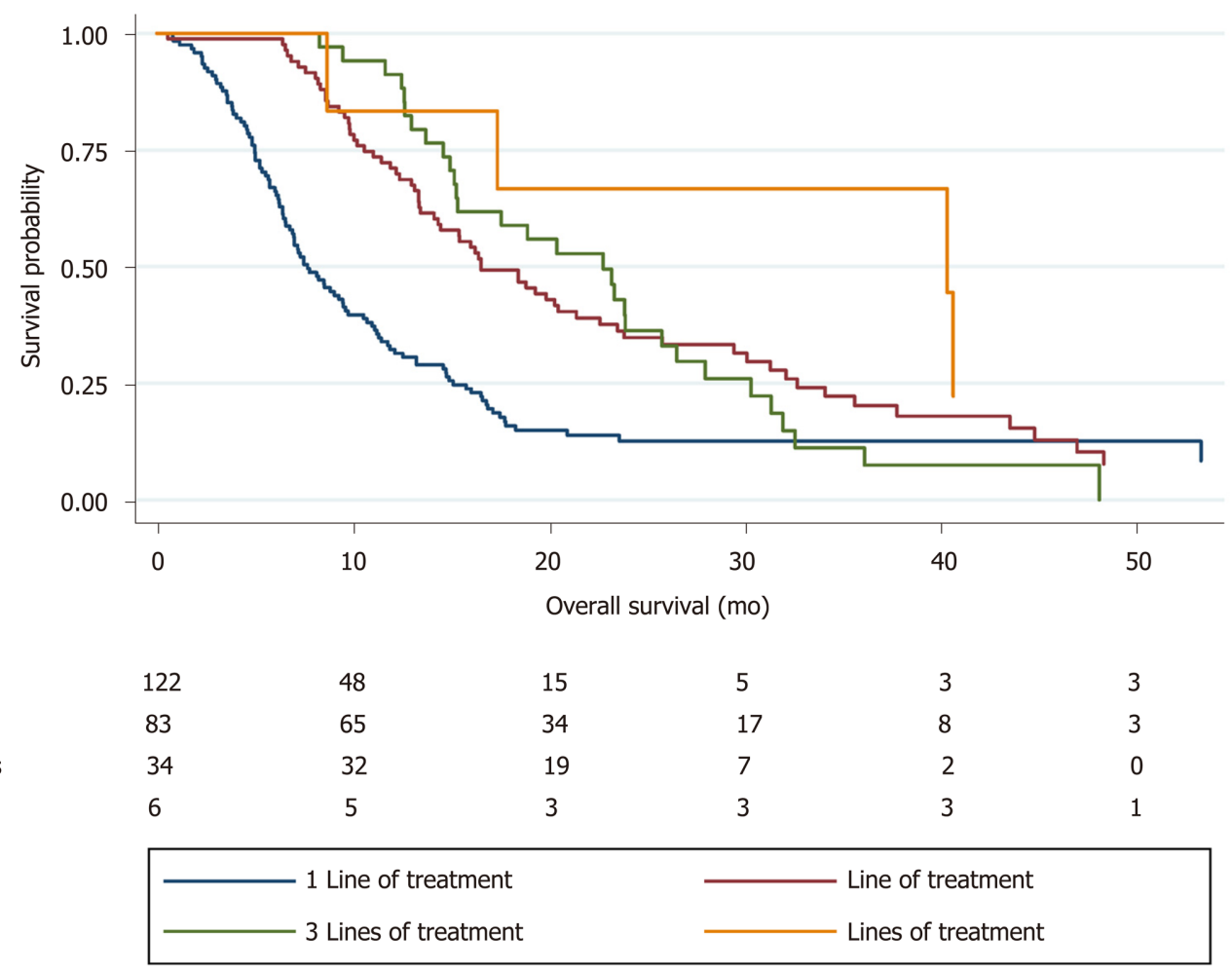

Figure 1 Overall survival by number of lines of treatment.

\section{ARTICLE HIGHLIGHTS}

\section{Research background}

Over the last decade, multiple agents have demonstrated efficacy for advanced esophagogastric cancer (EGC).

\section{Research motivation}

Despite the availability of later lines of therapy, there remains limited real-world data about the treatment attrition rates between lines of therapy.

\section{Research objectives}

We aimed to characterize the use and attrition rates between lines of therapy for patients with advanced EGC.

\section{Research methods}

We identified patients who received at least one cycle of chemotherapy for advanced EGC between July 1, 2017 and July 31, 2018 across six regional centers in British Columbia, Canada. Clinicopathologic, treatment, and outcomes data were extracted.

\section{Research results}

Of 245 patients who received at least one line of therapy, median age was 66 years (IQR 58.2-72.3) and 186 (76\%) were male, Eastern Cooperative Oncology Group (ECOG) performance status 0/1 (80\%), gastric vs GEJ (36\% vs 64\%). Histologies included adenocarcinoma (78\%), squamous cell carcinoma (8\%), and signet ring (14\%), with $31 \%$ HER2 positive. Seventy-two percent presented with de novo disease, and $25 \%$ had received previous chemoradiation. There was a high level of treatment attrition, with patients receiving only one line of therapy $(n=122,50 \%)$, two lines $(n=$ $83,34 \%)$, three lines $(n=34,14 \%)$, and four lines $(n=6,2 \%)$. Kaplan-Meier analysis demonstrated improved survival with increasing lines of therapy (median overall survival 7.7 vs 16.6 vs 22.8 vs 40.4 mo, $P<0.05$ ). On multivariable Cox regression, improved survival was associated with better baseline ECOG and increased lines of therapy $(P<0.05)$. 


\section{Research conclusions}

The steep attrition rates between therapies highlight the unmet need for more efficacious early-line treatment options for patients with advanced EGC.

\section{Research perspectives}

This real-world analysis demonstrating such steep attrition rates highlights the unmet need for more efficacious early-line treatment options.

\section{REFERENCES}

1 Siegel RL, Miller KD, Jemal A. Cancer statistics, 2018. CA Cancer J Clin 2018; 68: 7-30 [PMID: 29313949 DOI: $10.3322 /$ caac.21442]

2 Van Cutsem E, Sagaert X, Topal B, Haustermans K, Prenen H. Gastric cancer. Lancet 2016; 388: 26542664 [PMID: 27156933 DOI: 10.1016/S0140-6736(16)30354-3]

3 Napier KJ, Scheerer M, Misra S. Esophageal cancer: A Review of epidemiology, pathogenesis, staging workup and treatment modalities. World J Gastrointest Oncol 2014; 6: 112-120 [PMID: 24834141 DOI: 10.4251/wjgo.v6.i5.112]

4 Ilson DH. Advances in the treatment of gastric cancer. Curr Opin Gastroenterol 2018; 34: 465-468 [PMID: 30303856 DOI: 10.1097/MOG.0000000000000475]

5 Cunningham D, Starling N, Rao S, Iveson T, Nicolson M, Coxon F, Middleton G, Daniel F, Oates J, Norman AR; Upper Gastrointestinal Clinical Studies Group of the National Cancer Research Institute of the United Kingdom. Capecitabine and oxaliplatin for advanced esophagogastric cancer. N Engl J Med 2008; 358: 36-46 [PMID: 18172173 DOI: 10.1056/NEJMoa073149]

6 Koizumi W, Narahara H, Hara T, Takagane A, Akiya T, Takagi M, Miyashita K, Nishizaki T, Kobayashi O, Takiyama W, Toh Y, Nagaie T, Takagi S, Yamamura Y, Yanaoka K, Orita H, Takeuchi M. S-1 plus cisplatin versus S-1 alone for first-line treatment of advanced gastric cancer (SPIRITS trial): a phase III trial. Lancet Oncol 2008; 9: 215-221 [PMID: 18282805 DOI: 10.1016/S1470-2045(08)70035-4]

7 Fanotto V, Uccello M, Pecora I, Rimassa L, Leone F, Rosati G, Santini D, Giampieri R, Di Donato S, Tomasello G, Silvestris N, Pietrantonio F, Battaglin F, Avallone A, Scartozzi M, Lutrino ES, Melisi D, Antonuzzo L, Pellegrino A, Ferrari L, Bordonaro R, Vivaldi C, Gerratana L, Bozzarelli S, Filippi R, Bilancia D, Russano M, Aprile G. Outcomes of Advanced Gastric Cancer Patients Treated with at Least Three Lines of Systemic Chemotherapy. Oncologist 2017; 22: 1463-1469 [PMID: 28860412 DOI: 10.1634/theoncologist.2017-0158]

8 Fuchs CS, Tomasek J, Yong CJ, Dumitru F, Passalacqua R, Goswami C, Safran H, Dos Santos LV, Aprile G, Ferry DR, Melichar B, Tehfe M, Topuzov E, Zalcberg JR, Chau I, Campbell W, Sivanandan C, Pikiel J, Koshiji M, Hsu Y, Liepa AM, Gao L, Schwartz JD, Tabernero J; REGARD Trial Investigators. Ramucirumab monotherapy for previously treated advanced gastric or gastro-oesophageal junction adenocarcinoma (REGARD): an international, randomised, multicentre, placebo-controlled, phase 3 trial. Lancet 2014; 383: 31-39 [PMID: 24094768 DOI: 10.1016/S0140-6736(13)61719-5]

9 Shitara K, Özgüroğlu M, Bang YJ, Di Bartolomeo M, Mandalà M, Ryu MH, Fornaro L, Olesiński T, Caglevic C, Chung HC, Muro K, Goekkurt E, Mansoor W, McDermott RS, Shacham-Shmueli E, Chen X, Mayo C, Kang SP, Ohtsu A, Fuchs CS; KEYNOTE-061 investigators. Pembrolizumab versus paclitaxel for previously treated, advanced gastric or gastro-oesophageal junction cancer (KEYNOTE-061): a randomised, open-label, controlled, phase 3 trial. Lancet 2018; 392: 123-133 [PMID: 29880231 DOI: 10.1016/S0140-6736(18)31257-1]

10 Shitara K, Doi T, Dvorkin M, Mansoor W, Arkenau HT, Prokharau A, Alsina M, Ghidini M, Faustino C, Gorbunova V, Zhavrid E, Nishikawa K, Hosokawa A, Yalçın Ş, Fujitani K, Beretta GD, Cutsem EV, Winkler RE, Makris L, Ilson DH, Tabernero J. Trifluridine/tipiracil versus placebo in patients with heavily pretreated metastatic gastric cancer (TAGS): a randomised, double-blind, placebo-controlled, phase 3 trial. Lancet Oncol 2018; 19: 1437-1448 [PMID: 30355453 DOI: 10.1016/S1470-2045(18)30739-3]

11 Wilke H, Muro K, Van Cutsem E, Oh SC, Bodoky G, Shimada Y, Hironaka S, Sugimoto N, Lipatov O, Kim TY, Cunningham D, Rougier P, Komatsu Y, Ajani J, Emig M, Carlesi R, Ferry D, Chandrawansa K, Schwartz JD, Ohtsu A; RAINBOW Study Group. Ramucirumab plus paclitaxel versus placebo plus paclitaxel in patients with previously treated advanced gastric or gastro-oesophageal junction adenocarcinoma (RAINBOW): a double-blind, randomised phase 3 trial. Lancet Oncol 2014; 15: 1224-1235 [PMID: 25240821 DOI: 10.1016/S1470-2045(14)70420-6]

12 Le DT, Ott PA, Korytowsky B, Le H, Le TK, Zhang Y, Maglinte GA, Abraham P, Patel D, Shangguan T, Chau I. Real-world Treatment Patterns and Clinical Outcomes Across Lines of Therapy in Patients With Advanced/Metastatic Gastric or Gastroesophageal Junction Cancer. Clin Colorectal Cancer 2020; 19: 32 38.e3 [PMID: 31813769 DOI: 10.1016/j.clcc.2019.09.001]

13 Barzi A, Hess LM, Zhu YE, Liepa AM, Sugihara T, Beyrer J, Chao J. Real-World Outcomes and Factors Associated With the Second-Line Treatment of Patients With Gastric, Gastroesophageal Junction, or Esophageal Adenocarcinoma. Cancer Control 2019; 26: 1073274819847642 [PMID: 31056940 DOI: 10.1177/1073274819847642]

14 Hess LM, Michael D, Mytelka DS, Beyrer J, Liepa AM, Nicol S. Chemotherapy treatment patterns, costs, and outcomes of patients with gastric cancer in the United States: a retrospective analysis of electronic medical record (EMR) and administrative claims data. Gastric Cancer 2016; 19: 607-615 [PMID: 25792290 DOI: $10.1007 /$ s10120-015-0486-z]

15 Karve S, Lorenzo M, Liepa AM, Hess LM, Kaye JA, Calingaert B. Treatment Patterns, Costs, and Survival among Medicare-Enrolled Elderly Patients Diagnosed with Advanced Stage Gastric Cancer: Analysis of a 
Linked Population-Based Cancer Registry and Administrative Claims Database. J Gastric Cancer 2015; 15: 87-104 [PMID: 26161282 DOI: 10.5230/jgc.2015.15.2.87]

16 Ueno M, Doi A, Sunami T, Takayama H, Mouri H, Mizuno M. Delivery rate of patients with advanced gastric cancer to third-line chemotherapy and those patients' characteristics: an analysis in real-world setting. J Gastrointest Oncol 2019; 10: 957-964 [PMID: 31602334 DOI: 10.21037/jgo.2019.05.07]

17 Davidson M, Cafferkey C, Goode EF, Kouvelakis K, Hughes D, Reguera P, Kalaitzaki E, Peckitt C, Rao S, Watkins D, Chau I, Cunningham D, Starling N. Survival in Advanced Esophagogastric Adenocarcinoma Improves With Use of Multiple Lines of Therapy: Results From an Analysis of More Than 500 Patients. Clin Colorectal Cancer 2018; 17: 223-230 [PMID: 29980492 DOI: 10.1016/j.clcc.2018.05.014]

18 Fanotto V, Cordio S, Pasquini G, Fontanella C, Rimassa L, Leone F, Rosati G, Santini D, Giampieri R, Di Donato S, Tomasello G, Silvestris N, Pietrantonio F, Battaglin F, Avallone A, Scartozzi M, Lutrino ES, Melisi D, Antonuzzo L, Pellegrino A, Torri V, Aprile G. Prognostic factors in 868 advanced gastric cancer patients treated with second-line chemotherapy in the real world. Gastric Cancer 2017; 20: 825-833 [PMID: 28028664 DOI: 10.1007/s10120-016-0681-6]

19 Choi IJ. Endoscopic gastric cancer screening and surveillance in high-risk groups. Clin Endosc 2014; 47: 497-503 [PMID: 25505714 DOI: 10.5946/ce.2014.47.6.497]

20 Yoo KY. Cancer control activities in the Republic of Korea. Jpn J Clin Oncol 2008; 38: 327-333 [PMID: 18407932 DOI: 10.1093/jjco/hyn026]

21 Mulder KE, Ahmed S, Davies JD, Doll CM, Dowden S, Gill S, Gordon V, Hebbard P, Lim H, McFadden A, McGhie JP, Park J, Wong R. Report from the 17th Annual Western Canadian Gastrointestinal Cancer Consensus Conference; Edmonton, Alberta; 11-12 September 2015. Curr Oncol 2016; 23: 425-434 [PMID: 28050139 DOI: 10.3747/co.23.3384]

22 Kojima T, Muro K, Francois E, Hsu C, Moriwaki T, Kim S, Lee S, Bennouna J, Kato K, Lin S, Qin S, Ferreira P, Doi T, Adenis A, Enzinger PC, Shah MA, Wang R, Bhagia P, Kang SP, Metges J. Pembrolizumab vs chemotherapy as second-line therapy for advanced esophageal cancer: Phase III KEYNOTE-181 study. J Clin Oncol 2019; 37: 2-2 [DOI: 10.1200/JCO.2019.37.4_suppl.2]

23 Röcken C. Molecular classification of gastric cancer. Expert Rev Mol Diagn 2017; 17: 293-301 [PMID: 28118758 DOI: 10.1080/14737159.2017.1286985]

24 Cancer Genome Atlas Research Network. Comprehensive molecular characterization of gastric adenocarcinoma. Nature 2014; 513: 202-209 [PMID: 25079317 DOI: 10.1038/nature13480]

25 Nakajima M, Sawada H, Yamada Y, Watanabe A, Tatsumi M, Yamashita J, Matsuda M, Sakaguchi T, Hirao T, Nakano H. The prognostic significance of amplification and overexpression of c-met and c-erb B-2 in human gastric carcinomas. Cancer 1999; 85: 1894-1902 [PMID: 10223227 DOI: 10.1002/(SICI)1097-0142(19990501)85:93.0.CO;2-J]

26 Van Cutsem E, Karaszewska B, Kang YK, Chung HC, Shankaran V, Siena S, Go NF, Yang H, Schupp M, Cunningham D. A Multicenter Phase II Study of AMG 337 in Patients with MET-Amplified Gastric/Gastroesophageal Junction/Esophageal Adenocarcinoma and Other MET-Amplified Solid Tumors. Clin Cancer Res 2019; 25: 2414-2423 [PMID: 30366938 DOI: 10.1158/1078-0432.CCR-18-1337]

27 Desai J, Kortmansky JS, Segal NH, Fakih M, Oh D, Kim K, Rahma OE, Ko AH, Chung HC, Alsina M, Yeh K, Li S, Al-Sakaff N, Patel J, Barak H, Wang J, Zhang X, Bleul C, Cha E, Lee J. MORPHEUS: A phase Ib/II study platform evaluating the safety and clinical efficacy of cancer immunotherapy (CIT)-based combinations in gastrointestinal (GI) cancers. J Clin Oncol 2019; 37: TPS467-TPS467 [DOI: 10.1200/JCO.2019.37.4_suppl.TPS467] 


\section{DS \\ Baishideng ${ }^{\circledR}$}

Published by Baishideng Publishing Group Inc

7041 Koll Center Parkway, Suite 160, Pleasanton, CA 94566, USA

Telephone: +1-925-3991568

E-mail: bpgoffice@wignet.com

Help Desk: https:/ /www.f6publishing.com/helpdesk

https://www.wjgnet.com

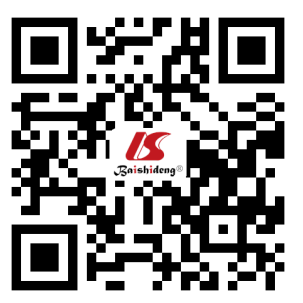

